\title{
Neutrophil Turnover in Normal Rabbit Lungs
}

\author{
Allen B. Cohen, Michael Rossi, Dagmar Geczy, and linda Knight, \\ Departments of Medicine, Physiology, and Nuclear Medicine, Temple \\ University School of Medicine, Philadelphia, Pennsylvania 19140
}

A B S T R A C T Neutrophil turnover was studied in the blood and alveoli of normal rabbits. Blood neutrophil turnover was examined by two different methods. In the first method, donor rabbit neutrophils were labeled in vivo by injecting tritium-labeled thymidine intravenously. After $72 \mathrm{~h}$ recipient rabbits received blood from the donors. The decline of the specific radioactivity of blood neutrophils was used to determine that their half-life was $4.03 \mathrm{~h}$. In the second method, rabbit peritoneal exudative neutrophils were elicited with oyster glycogen. These cells were labeled with ${ }^{111}$ Indium oxine and infused into the blood of recipient animals. By their decline in specific radioactivity, the half-life of the blood neutrophil was $4.08 \mathrm{~h}$. These halflives are not significantly different.

Lung lavage was performed on the animals that received the ${ }^{111}$ Indium-labeled neutrophils and the turnover time of the lung neutrophil was found to be 2.63 h. The turnover of the alveolar neutrophil pool accounted for only $0.19 \%$ of the total turnover of the blood neutrophils. Therefore, the lung appears to contribute only minimally to the total capacity of the body to dispose of neutrophils.

\section{INTRODUCTION}

The neutrophil is a short-lived cell that matures in the bone marrow and has a half-life in the blood of 3.2$6.7 \mathrm{~h}$, depending on the species (1-3). Although the synthesis and disappearance of blood neutrophils has been extensively studied, relatively few studies have been done on the fate of neutrophils that leave the circulatory system. This report focuses on the movement of neutrophils from the blood to the alveoli of normal rabbits. It has been known for decades that neutrophils inhabit the alveoli of normal animals (4, 5 ) and people (6). Bierman and his colleagues (5, 7-9) measured differences in circulating neutrophil concentrations in pulmonary arterial and peripheral arterial blood and suggested that the pulmonary circulation was capable of rapidly removing, storing, or

Received for publication 27 July 1981 and in revised form 2 October 1981 delivering vast quantities of leukocytes. Lawrence (10) stressed that the lung is not the only site of neutrophil egress from the circulation and that neutrophil uptake in the lung may be different than in other organs.

Few investigators have studied the movements of neutrophils through normal lungs. Previous work from this laboratory (11) has shown that movement of neutrophils into the lungs is not of sufficient magnitude to result in differences in neutrophil concentration between right and left ventricular blood. In addition, the poolsize of neutrophils in the airspaces of normal rabbits is small $\left(\sim 6.11 \times 10^{4}\right.$ neutrophils in the airspaces per gram of lung tissue) (11). Although the route that the neutrophils take into the lungs of normal animals is not known, in animals in which chemotaxis has been stimulated in the alveoli, the neutrophils enter the interstitium from the lung capillaries, traverse the alveolar-capillary membrane, and exit between type I and II cells (12). The process causes no derangements in normal lung architecture. The contribution of alveolar neutrophils to the total egress of neutrophils from the blood or to the metabolism of the lung can be estimated if the turnover rate of the airspace pool is measured. We, therefore, measured the turnover rate of this pool of neutrophils in normal rabbits.

\section{METHODS}

Kinetics of neutrophils labeled with tritiated thymidine. The half-life of the blood neutrophil was determined in two ways. In the first approach, the method of Price and Dale was used (1). New Zealand White rabbits weighing $\sim 3 \mathrm{~kg}$ were used for all experiments. Blood neutrophils were labeled by injecting donor rabbits intravenously with $2 \mathrm{mCi}$ (50 Ci/mmol) of tritiated thymidine $\left[{ }^{3} \mathrm{H}\right]$ thymidine (New England Nuclear, Boston, MA). $72 \mathrm{~h}$ after the injection, 30 $\mathrm{ml}$ of blood was withdrawn from the central artery of the ear into a plastic syringe containing acid citrate-dextrose as an anticoagulant. An equivalent amount of blood was withdrawn from the recipient and the blood from the donor was infused over 5 min into the marginal vein of the ear. $10 \mathrm{ml}$ of blood was withdrawn at intervals. The neutrophils were separated by the method of Price and Dale (1) and solubilized in $1 \mathrm{ml}$ of protosol (New England Nuclear). The solution was then mixed with $15 \mathrm{ml}$ of Biofluor (New England Nuclear) and counted in an ISOCAP 300 liquid scintillation spectrometer (Searle Radiographics Inc., Des Plaines, IL). Quench was corrected for by the external standards ratio method. Values were normalized for animal size and initial 
dose of radioactivity. The radioactivity of these neutrophils was too low to adequately quantitate in the lung wash cells. Therefore, a second method of labeling was used.

General plan of lung neutrophil kinetic experiments. Neutrophils were attracted to the peritoneal cavity of donor rabbits with oyster glycogen and washed from this space. The neutrophils were then labeled with ${ }^{111}$ Indium $\left({ }^{111} \mathrm{In}\right)$ and infused into recipients. The recipients had blood drawn for blood neutrophil kinetic studies periodically until their lungs were due to be washed. At different times after the infusion, the animals were sacrificed and their lungs were washed to determine the specific activity of the neutrophils in the alveoli. The changes in specific activity of the blood and lung neutrophils were used to compute the lung neutrophil turnover rate.

Details of experiments. In the second method ( ${ }^{111}$ In oxine method), neutrophils were attracted to the peritoneal cavity by infusing $100 \mathrm{ml}$ of a $0.9 \%$ solution of sodium chloride containing oyster glycogen type II (Sigma Chemical Co., St. Louis, MO) at $1 \mathrm{~g} /$ liter (13). After $4 \mathrm{~h}$ the animals were sedated with $0.55 \mathrm{ml} / \mathrm{kg}$ of Innovar Vet, containing Fentanyl $(0.4 \mathrm{mg} / \mathrm{ml})$ and Droperidol $(20 \mathrm{mg} / \mathrm{ml})$ (Pitman-Moore, Inc.), given intramuscularly. An additional $200 \mathrm{ml}$ of sodium chloride, $0.9 \%$, was infused into the peritoneal cavity, and the fluid was drained out. The cells, 95-98\% neutrophils, were labeled with ${ }^{111}$ In by the method of Thakur et al. (14). After washing twice in isotonic, sterile sodium chloride, 1 $\mathrm{mCi}$ of ${ }^{111}$ In oxine (Mediphysics, Emoryville, CA) was added and the cells were cooled in ice and mixed by inverting every $15 \mathrm{~s}$ for $15 \mathrm{~min}$. After washing three times in isotonic sodium chloride, the cells were counted in a Coulter counter (Coulter Electronics, Hialeah, FL), suspended in $5 \mathrm{ml}$ of isotonic sodium chloride, and infused into a marginal vein in the ear of the recipient animal. At different times before the animal was killed, $1 \mathrm{ml}$ of blood was removed from the central artery of the ear and mixed with $0.1 \mathrm{ml}$ of heparin sulfate, $1,000 \mathrm{U} / \mathrm{ml}$. Leukocytes were counted and blood smears were made for determination of the percentage of each cell type present. At the time of sacrifice, the animals were sedated with Innovar Vet as noted above and anesthetized with sodium pentobarbitol, $50 \mathrm{mg} / \mathrm{ml}$, in isotonic sodium chloride infused through a slowly dripping intravenous infusion until stimulation evoked no response. Then the abdomen was opened and the animal was exsanguinated through the aorta. This method of euthanasia was necessary to achieve erythrocyte-free lung washes. After exsanguination, the trachea was exposed and cannulated with a plastic tube. The lungs were washed by repeated infusion and aspiration of 20-ml aliquots of sterile sodium chloride until a total of $140 \mathrm{ml}$ of fluid had been infused and as much as possible recovered. The average return was $130 \mathrm{ml}$ of fluid. The total number of cells was counted, and a sample of the cells was pelleted onto glass microscope slides with a Cytocentrifuge (Shandon Southern Instruments Inc., Sewickley, PA) and stained with Giemsa stain. 1,000 cells were counted in each determination of the percentage of each cell type in the lung wash. The radioactivity in the remaining cells was counted with a model 1185 gamma-radiation spectrometer (Searle Radiographics Inc.).

Turnover rates were calculated by the method of Zilversmit (15). The following definitions are used: fractional turnover rate $(k)=$ the fraction of the neutrophils of the alveolar compartment turned over per unit time.

Turnover time $\left(t_{t}\right)=$ the time required for the turnover of a quantity of neutrophils equal to the quantity of neutrophils in the alveoli; corresponds to the average lifetime of a neutrophil in the alveoli.

Half-life $\left(t_{1 / 2}\right)=$ the time necessary for the neutrophil specific activity to be reduced by one half.
Specific activity of the blood neutrophil $\left(S_{B}\right)=$ the radioactivity, in desintegrations per minute per $10^{3}$ or $10^{6}$ cells, as noted in Results.

Specific activity of the alveolar neutrophil $\left(S_{\mathbf{A}}\right)=$ the quantity of radioactivity divided by the number of neutrophils per unit volume of lung wash. Although it is not possible to isolate the small number of neutrophils in the lung wash, all of the radioactivity was in the cell pellet, and we have shown in earlier studies that lung macrophages do not phagocytize neutrophils in significant quantities (11).

Given these definitions, the following equations can be used to compute the turnover time:

$$
k=\frac{S_{B_{t_{2}}}-S_{B_{t_{2}}}}{\int_{t_{2}}^{t_{1}}\left(S_{B}-S_{A}\right) d_{t}}
$$

and

$$
\frac{1}{k}=t_{1}=1.44 t_{1 / 2}
$$

The assumptions of the model included are $(a)$ that the movements of neutrophils between the compartments are in a steady state and $(b)$ that neutrophils leave the circulation to enter the alveoli in a random fashion but $(c)$ do not then reenter the blood. The steady-state assumption will be discussed under Results. The latter two assumptions are excellently fulfilled by neutrophils (16).

Curves of decays of blood radioactivity are drawn from least-squares regression of the log of the specific activity of the blood neutrophils (17). The significance of differences between the slopes of the blood specific activity curves was determined by the $t$ test for the null hypothesis (17).

\section{RESULTS}

Peripheral blood leukocyte measurements. Cell concentrations were expressed as cells per cubic microliter unless otherwise noted. After the infusion of ${ }^{111}$ In-labeled neutrophils, the leukocyte concentration dropped from an average of $6,201(\mathrm{SE}=481)$ to an average of $4,821(\mathrm{SE}=322)$ (Fig. 1). It then rose to a high point of $9,325(\mathrm{SE}=2,341)$ at $2 \mathrm{~h}$ and dropped toward normal. The young neutrophils or bands rose from an initial level of $1.3 \%(\mathrm{SE}=0.35$ ) to a high level of $6.7 \%(\mathrm{SE}=0.35)$ of the total leukocytes at $2 \mathrm{~h}$ and then declined. To determine when a steady state was reestablished, a $t$ test for significance of difference between the mean values of the neutrophil concentrations and percentage of bands in blood drawn before the neutrophil infusion was compared with those measured in blood drawn 4 and $5 \mathrm{~h}$ after the infusion. The mean neutrophil concentrations were 3,770 (SE $=338), 5,458(\mathrm{SE}=586)$, and 4,551 ( $\mathrm{SE}=554)$, in blood drawn before the infusion and at 4 and $5 \mathrm{~h}$ after the infusion, respectively. The neutrophil concentration was significantly more at $4 \mathrm{~h}(P=0.01)$ but was not significantly different at $5 \mathrm{~h}(P=0.12)$. The mean percentage of bands was $1.3 \%(\mathrm{SE}=0.35), 4.7 \%$ (SE $=2.0)$, and $3.1 \%(\mathrm{SE}=1.6)$ in blood drawn before the infusion and at 4 and $5 \mathrm{~h}$ after the infusion, respectively. The percentage of bands in blood drawn from 


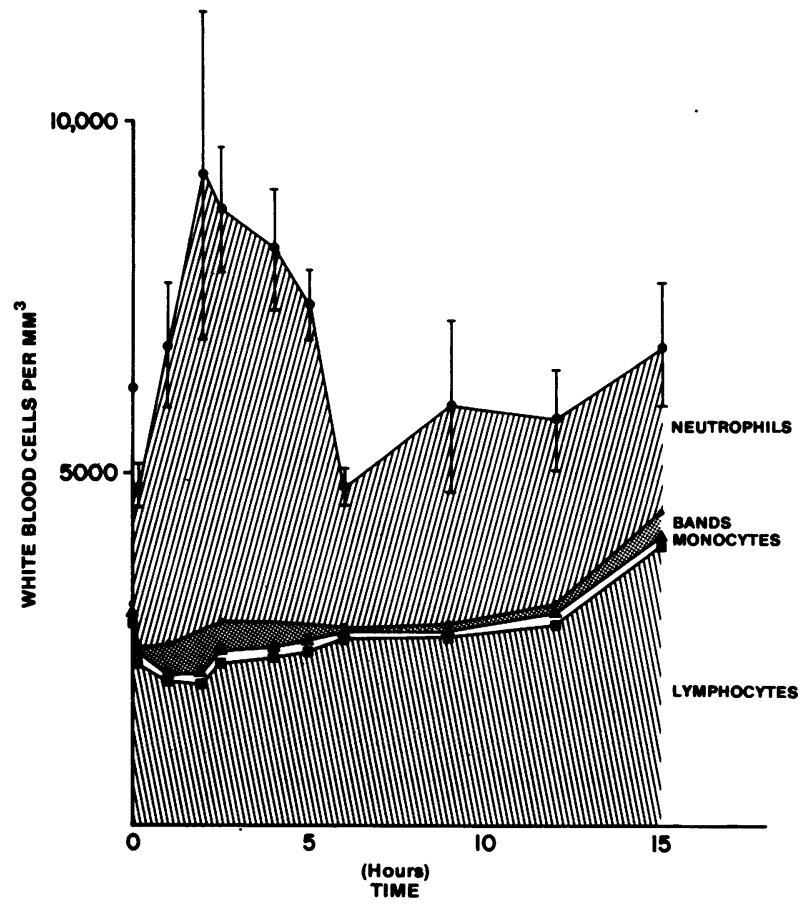

Figure 1 Blood leukocyte concentrations in rabbits after the infusion of ${ }^{111}$ In-labeled peritoneal neutrophils. Bars indicate standard errors.

the rabbits before the neutrophil infusion was also significantly more at $4 \mathrm{~h}(P=0.04)$ and was not significantly different at $5 \mathrm{~h}(P=0.14)$.

These data indicate that the animals returned to a steady state at about $5 \mathrm{~h}$ after the infusion.

Blood specific activity curves. Blood specific activity curves were determined in the rabbits receiving both the $\left[{ }^{3} \mathrm{H}\right]$ thymidine-labeled neutrophils and the ${ }^{111}$ In-labeled cells (Fig. 2).

The line generated from the $\left[{ }^{3} \mathrm{H}\right]$ thymidine-labeled neutrophils was determined from three to six observations per time point and nine time points were sampled from $10 \mathrm{~min}$ to $12 \mathrm{~h}$. The specific activity of the blood neutrophil at $t=0$ was calculated by extrapolating the decrease in blood neutrophil specific radioactivity with time back to the time of infusion (Fig. 2 ). Because the first two points reflect the usual early drop in leukocytes, they were not included in the calculation. An estimated $43 \%$ of the radioactivity injected in neutrophils remained in the circulation as calculated by the method of Raab et al. (3). The halflife of the neutrophils was $4.03 \mathrm{~h}$.

The line generated from the ${ }^{111}$ In-labeled neutrophils was determined from as many as 23 observations in the 10 -min point to as few as 4 observations for the 15-h point because blood samples were drawn from each animal until it was killed for the lung wash. The results of this study are shown in Fig. 2. A half-life of

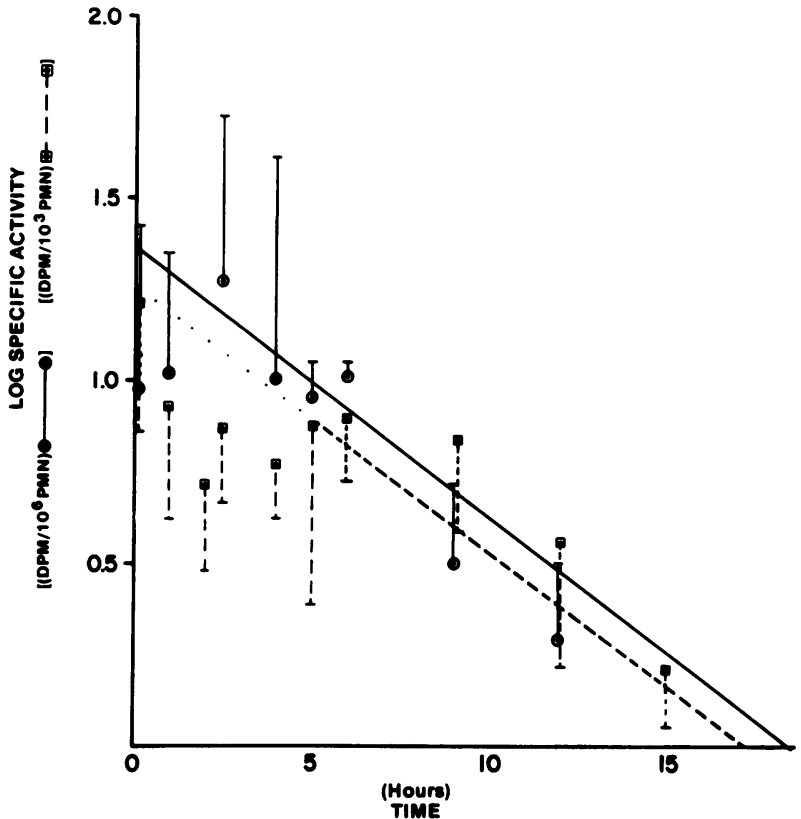

Figure 2 Disappearance of labeled blood neutrophils. Specific activity of blood neutrophils in rabbits (see text for details). Bars indicate standard errors. Donors: $\odot-\odot$, $\left[{ }^{3} \mathrm{H}\right]$ thymidine-labeled blood; $\square-\square,{ }^{111}$ In-labeled peritoneal neutrophils.

4.08 was determined for the neutrophils. The slopes of the two lines are in excellent agreement.

After the infusion of the ${ }^{111}$ In-labeled neutrophils, the total radioactivity dropped and recovered by $5 \mathrm{~h}$ (Fig. 3). Therefore, the early phase of the curve was excluded in the calculation of the half-life of the neutrophils. The correlation coefficient of the decline in radioactivity is 0.93 and the half-life of the neutrophils calculated from this curve is $5.1 \mathrm{~h}$. The slope of this line is not significantly different from the slope of the decline in specific activity of tritiated and Indium-labeled neutrophils (Fig. 2) $(P=0.12$ and 0.09 , respectively). When the line is extrapolated to the time of infusion, there were $6.76 \times 10^{4} \mathrm{dpm} / \mathrm{ml}$ of blood. The average blood volume of the rabbits was $175 \mathrm{ml}$. Therefore, the total blood radioactivity was $1.18 \times 10^{7}$ $\mathrm{dpm} / \mathrm{ml}$. The average radioactivity injected was 2.6 $\times 10^{7} \mathrm{dpm}\left(\mathrm{SE}=5.6 \times 10^{7}\right)$. Therefore, the radioactivity retained in the blood was $45.4 \%$ of that injected. This value was similar to that calculated for the $\left[{ }^{3} \mathrm{H}\right]$ thymidine-labeled neutrophils.

Alveolar neutrophil specific activity was determined at seven times, using four animals for each time (Fig. 4). The curves are visual estimates of the shape and position of the points. Use was made of the points between 5 and $9 \mathrm{~h}$ in order to make the estimation after the animals had returned to a steady state in terms of the blood neutrophil concentrations and quantities. The fractional turnover rate was estimated 


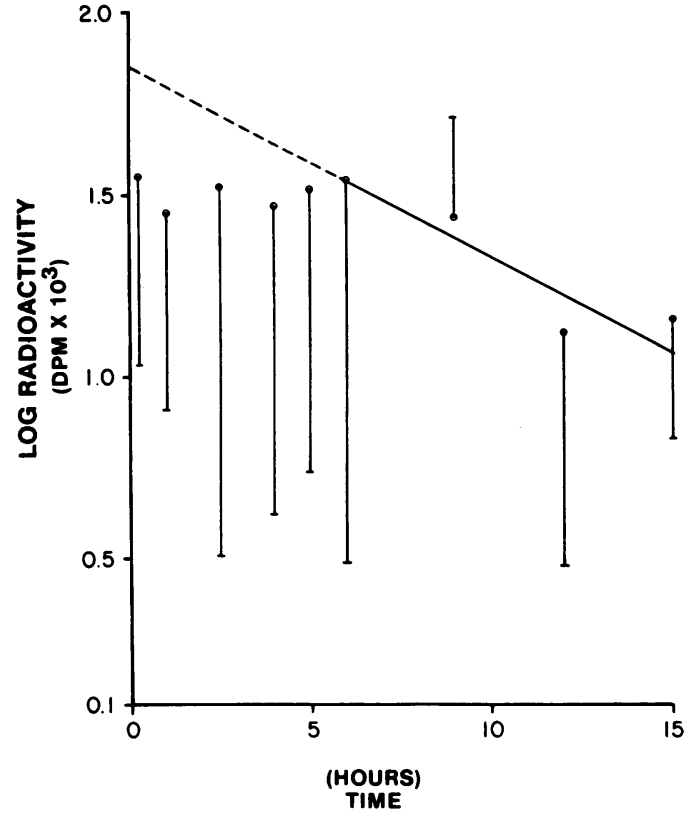

FIGURE 3 Radioactivity in the blood following infusion of ${ }^{111}$ In-labeled neutrophils. Bars indicate standard errors. The upwardly directed bar indicates a standard error $<1$ that had a negative logarithm.

to be $0.38 \mathrm{~h}^{-1}$. These data give a turnover time of 2.63 $h$. This method of calculating turnover time values has the advantage that the results are not dependent on the shapes of the curves and are computed directly from the data.

\section{DISCUSSION}

These experiments are the first quantitative direct estimates of the turnover of neutrophils in an extravascular pool. The assumptions inherent in the model are suited to the study of neutrophils that leave the circulation in a random fashion and do not return to it $(16,18,19)$. The method used herein has the advantage that it requires no assumptions about the shapes of the curves generated. The curves shown in Fig. 4 demonsrate a proper precursor/product relationship, notwithstanding the relatively wide standard deviations inherent in the methods used. The major liability in the method is that it requires highly intensive labor and is expensive. Therefore, it does not lend itself to the study of the effects of manipulations on the turnover time. Labeling the neutrophils with $\left[{ }^{3} \mathrm{H}\right]$ thymidine has the advantage of using blood neutrophils that have been minimally manipulated, and therefore, they serve as a good standard by which to judge the rate of disappearance of other neutrophil preparations from the blood. These data show that the half-life of the neutrophils labeled and acquired by these two different methods do not differ significantly. ${ }^{111}$ In-labeled

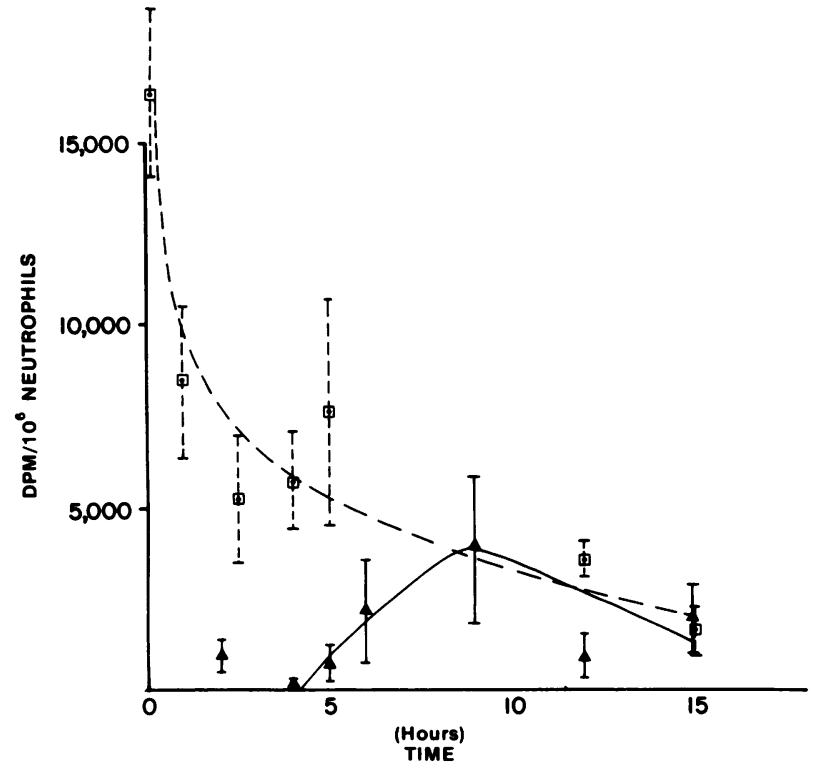

FIgURE 4 Neutrophil specific activity. Specific activity of lung $(\Delta)$ and blood $(\square)$ neutrophils in rabbits after the infusion of ${ }^{111}$ In-labeled peritoneal neutrophils. (Bars indicate standard errors).

peritoneal neutrophils, therefore, disappear from the blood in a manner similar to ${ }^{3} \mathrm{H}$-labeled neutrophils.

Both the curves of the disappearance of radioactivity of ${ }^{111}$ In-labeled neutrophils from the blood and the decline in neutrophil specific activity demonstrated an initial disappearance of the cells from the circulation. Statistical analysis of neutrophil and band concentrations in the blood and inspection of the curves referred to above demonstrated that the animals had returned to a steady state by about the fifth hour. These curves are in good agreement with the behavior of Indiumlabeled neutrophils infused into dogs $(20)$, but the cells do not exhibit the profound drop before the return to normal that is seen in hamsters $(21)$. In addition, $\sim 45 \%$ of the neutrophil remain in the circulating neutrophil pool, suggesting that there is not a population of damaged neutrophils that are migrating into the lungs. However, the $\left[{ }^{3} \mathrm{H}\right]$ thymidine-labeled neutrophils were not sufficiently highly labeled to detect the radioactivity reliably in the lung wash cells. Therefore, the ${ }^{111}$ In-labeled peritoneal neutrophils were used in the studies of lung neutrophil turnover rates.

The results have importance to several areas of investigation. Bierman and colleagues $(5,9)$ suggested that the lung was a significant site of egress for neutrophils. This hypothesis can be examined in the following manner. The average basal neutrophil concentration of the blood of the rabbits was $6.2 \times 10^{6}$ cells/ $\mathrm{ml}$ with $50 \%$ neutrophils. If the rabbits had an average blood volume of $\sim 57 \mathrm{ml} / \mathrm{kg}(22)$, and the circulating neutrophil pool represented $45 \%$ of the total blood 
neutrophil pool, then the total blood granulocyte pool was $\sim 3.9 \times 10^{8}$ cells $/ \mathrm{kg}$. Because the average half-life of the blood neutrophil in this study was $4.5 \mathrm{~h}$, the average turnover time was $6.48 \mathrm{~h}$ or 3.7 turnovers per day. Then, about $1.44 \times 10^{9}$ blood neutrophils turn over per kilogram of rabbit each day. A similar calculation can be carried out for neutrophils in air spaces. The pool size of alveolar neutrophils is 6.11 $\times 10^{4} \mathrm{~g} /$ lung $(\mathrm{SD}=3.6)(11)$. There were $4.94 \mathrm{~g}$ of lung $/ \mathrm{kg}$ weight of rabbit (11), and a turnover time of $2.63 \mathrm{~h}$, or 9.1 turnovers per day. Therefore, $2.75 \times 10^{6}$ neutrophils turn over per kilogram of rabbit in the lungs per day. Therefore, $0.19 \%$ of the total neutrophil turnover of the blood occurs in the lungs, and Bierman's hypothesis $(5,7-9)$ is clearly untenable.

A second important ramification of this work is that a small but rapidly turning over pool of neutrophils has been demonstrated in alveoli. If these cells release their elastase into the lungs during migration into the airspaces or during egress from the lungs this low level of elastase could result in emphysema in individuals who had low alveolar levels of alpha-1-antitrypsin either genetically (23) or as a result of smoking cigarettes $(24,25)$.

\section{ACKNOWLEDGMENT}

This paper was supported by grant 5 PO1 HL20994 from the Lung Division of the National Heart, Lung and Blood Institute.

\section{REFERENCES}

1. Price, T. H., and D. C. Dale. 1977. Neutrophil preservation. The effect of short-term storage on in vivo kinetics. J. Clin. Invest. 59: 475-480.

2. Athens, J. W., O. P. Haab, S. O. Raab, A. M. Mauer, H. Ashenbrucker, G. E. Cartwright, and M. M. Wintrobe. 1961. Leukokinetic studies. IV. The total blood circulating and marginal granulocyte pools and the granulocyte turnover rate in normal subjects. J. Clin. Invest. 40: 989 .

3. Raab, S. O., J. W. Athens, O. P. Haab, D. R. Boggs, H. Ashenbrucker, G. E. Cartwright, and M. M. Wintrobe. 1964. Granulokinetics in normal dogs. Am. J. Physiol. 206: 83-88.

4. Ambrus, J. C., and C. M. Ambrus. 1958. Regulation of the elimination of leukocytes. Brookhaven Symp. Biol. H10: 84-95.

5. Bierman, H., K. Kelly, and F. Cordes. 1955. The sequestration and visceral circulation of leukocytes in man. Ann. N. Y. Acad. Sci. 59: 850-862.

6. Pratt, S., T. N. Finley, M. H. Smith, and A. Ladman. 1969. A comparison of human alveolar macrophages and pulmonary surfactant (?)-obtained from the lungs of smokers and nonsmokers by endobronchial lavage. Anat. Rec. 163: 497-508.

7. Bierman, H., K. Kelly, F. Cordes, R. Byron, J. Polnemus, and S. Rappaport. 1952. The release of leukocytes and platelets from the pulmonary circulation by epinephrine. Blood. 7: 683-692.
8. Bierman, G. R., K. Kelly, F. Cordes, N. Petrakis, H. Kass, and E. Sun. 1952. The influence of respiratory movements upon the circulating leukocyte. Blood. 7: 533-544.

9. Bierman, H. R. 1955. The hematologic role of the lung in man. Am. J. Surg. 89: 139-140.

10. Lawrence, J. S. 1941. Leukopenia. A discussion of its various modes of production. JAMA (J.Am. Med. Assoc.). 116: 478-484.

11. Cohen, A. B., G. Batra, R. Petersen, J. Podany, and D. Nguyen. 1979. Size of the pool of alveolar neutrophils in normal rabbit lungs. J. Appl. Physiol. 47: 440-444.

12. Damiano, V. V., A. B. Cohen, A. Tsang, G. Batra, and R. Petersen. 1980. A morphologic study of the influx of neutrophils into dog lung alveoli after lavage with sterile saline. Am. J. Pathol. 100: 349-364.

13. Cohn, Z. A., and S. J. Morse. 1959. Interactions between rabbit polymorphonuclear leukocytes and staphylocci. J. Exp. Med. 110: 419-443.

14. Thakur, M. L., A. W. Segal, L. Louis, M. J. Welch, J. Hopkins, and T. J. Peters. 1977. Indium-III-labeled cellular blood components: mechanism of labeling and intracellular location in human neutrophils. J. Nucl. Med. 18: 1022-1026.

15. Zilversmit, D. B. 1960. The design and analysis of isotope experiments. Am. J. Med. 29: 832-848.

16. Uchida, T. 1971. Leukokinetic studies in peripheral blood I. Neutrophilic granulocyte kinetics in normal man. Acta Haematol. Jpn. 34: 164-185.

17. Dixon, W. J., and F. J. Massey. 1969. In Regression and Correlation. Introduction to statistical analysis. McGraw-Hill Book Company, New York. 193-222.

18. Athens, J. W. 1970. Neutrophil granulocyte kinetics and granulopoiesis. In Regulation of Hematopoiesis. A. S. Gordon, editor. Meredith Corporation, New York. 11431166.

19. Grant, L. 1965. The sticking and emigration of white blood cells in inflammation. In The Inflammatory Process. B. W. Zweifach, L. Grant and R. T. McClusky, editors. Academic Press, Inc., New York. 197-244.

20. Thakur, M. L., R. E. Coleman, and M. J. Welch. 1977. Indium-111-labeled leukocytes for the localization of abcesses: preparation, analysis, tissue distribution, and comparison with galliium-67 citrate in dogs. J. Lab. Clin. Med. 89: 217-228.

21. Desai, U., H. Kreutzer, C. Showell, Arroyave, and P. Ward. 1979. Acute inflammatory pulmonary reactions induced by chemotactic factors. Am. J. Pantol. 96: 7184.

22. Armin, J., R. T. Grant, H. Pels, and E. G. Reeve. 1952. The plasma cell and blood volumes of albino rabbits as estimated by the dye (T1824) and ${ }^{32} \mathrm{P}$ marked cell methods. J. Physiol. (Lond.). 116: 59-73.

23. Gadek, J. E., G. A. Hunninghake, G. A. Fells, R. L Zimmerman, B. A. Keough, and R. G. Crystal. 1900. Evaluation of the protease-antiprotease theory of human destructive lung disease. Bull. Eur. Physiopathol. Respir. 16(Suppl.): 27-40.

24. Gadek, J. E., G. A. Fells, and R. G. Crystal. 1979. Cigarette smoking induces functional antiprotease deficiency in the lower respiratory tract of humans. Science (Wash., D. C.). 206: 1315-1316.

25. Janoff, R. H., H. Carp, D. K. Lee, and R. T. Drew. 1979. Cigarette smoke inhalation decreases alpha-1-antitrypsin activity in rat lung. Science (Wash., D. C.). 206: 1313-1314. 